\author{
Maria WESOLOWSKA ${ }^{1}$ \\ Anna KACZMAREK ${ }^{2}$
}

\title{
ANALIZA ZMIAN MIKROSTRUKTURY ZAPRAW W MURACH Z CEGLY KLINKIEROWEJ PO DŁUGOTRWAŁEJ EKSPOZYCJI NA POLSKIE WARUNKI KLIMATYCZNE
}

\begin{abstract}
Mury licowe podlegają ciągłym wpływom czynników pochodzących z otaczającego środowiska. Oddziaływania te przyczyniają się do destrukcji materiału, obniżając ich trwałość użytkową. Zaprawy należą do grupy materiałów aktywnych chemicznie, podlegającym korozji zewnętrznej i wewnętrznej. Do korozji zewnętrznej zalicza się wszystkie te przypadki, w których zaprawa narażona jest na niekorzystne czynniki zewnętrzne (gazowy $\mathrm{CO}_{2}$, kwaśne deszcze, zmienne temperatury przekraczające często punkt $0^{\circ} \mathrm{C}$, roztwory rozpuszczalnych soli mineralnych pochodzących z otaczających elementów). Przyczyną korozji wewnętrznej są same składniki zapraw. Wymienione czynniki istotnie wpływają na zmiany mikrostruktury zapraw. Proces ten jest rozłożony w czasie.

Analizę przeprowadzono na stanowisku poligonowym zlokalizowanym na terenie Uniwersytetu Technologiczno - Przyrodniczego w Bydgoszczy. Do analizy wytypowano 3 mury licowe na różnych zaprawach. W kolejnych latach funkcjonowania murów obserwowano pojawianie się wykwitów o różnym zakresie i nasileniu. Zebrane informacje pozwoliły na ustalenie obszaru o najwyższej intensywności wykwitów. Po dziesięciu latach, dla każdego muru, z wytypowanego miejsca pobrano próbki zapraw, dla których zbadano mikrostrukturę metodą porozymetrii rtęciowej. Uzyskane wyniki posłużyły do oceny zmian udziału mezo- i makro-porów w badanych zaprawach powstałych w wyniku oddziaływania środowiska zewnętrznego.
\end{abstract}

Słowa kluczowe: mur licowy, mikrostruktura zapraw, oddziaływanie środowiska

\section{Wprowadzenie}

W przypadku murów licowych, które z definicji powinny charakteryzować się wysoką estetyką i trwałością, zapewnienie odpowiednich warunków eksploa-

\footnotetext{
${ }^{1}$ Autor do korespondencji/corresponding author: Maria Wesołowska, Uniwersytet Technologiczno - Przyrodniczy, WBAiIŚ, ul. Kaliskiego 7, 85-796 Bydgoszcz, 52 3408679, marysia@utp.edu.pl

2 Anna Kaczmarek, Uniwersytet Technologiczno - Przyrodniczy, WBAiIŚ, ul. Kaliskiego 7, 85-796 Bydgoszcz, 52 3408679, anna.kaczmarek@utp.edu.pl
} 
tacji stanowi poważny problem techniczny. Konstrukcja murów powinna być przygotowana do pracy w skrajnych warunkach wilgotnościowo - temperaturowych. Pewne sugestie dotyczące tej problematyki zostały zawarte w Eurokodzie 6 [1]. Wpływ środowiska opisano klasami ekspozycji, które określają bezpośrednio czynniki oddziaływujące na konstrukcję. Według powyższej klasyfikacji mury licowe znajdujące się $\mathrm{w}$ kontakcie $\mathrm{z}$ gruntem narażone są na środowisko agresywne chemicznie, z wilgocią i zamarzaniem. Stąd też niezwykle istotnym jest właściwe rozwiązanie strefy kontaktu muru z podłożem, które powinno ograniczać wpływ deszczu (woda rozbryzgowa), możliwości migracji związków mineralnych z gruntu i z ewentualnej opaski betonowej.

Duże znaczenie ma też rodzaj użytej zaprawy, która należy do materiałów aktywnych chemicznie. Analogicznie jak dla betonu, można wyróżnić dwa rodzaje korozji: zewnętrzną środowiskową i wewnętrzną [2]. Podstawową przyczyną korozji są czynniki wewnętrzne, do których zalicza się właściwości wbudowanych materiałów i ich wzajemne interakcje $[3,4,5]$. Badania laboratoryjne [6] dotyczące migracji aktywnych chemicznie związków wskazują, że rozpuszczony wodorotlenek wapnia jest ługowany z zaprawy i wysycha na powierzeniach licowych muru ulegając karbonatyzacji.

Używane współcześnie klinkierowe elementy licowe charakteryzują się bardzo niską nasiąkliwości (poniżej 6\%) i początkową absorpcją wody. Wzrasta zatem rola zaprawy w ograniczeniu przedostawania się wilgoci do wnętrza muru. Stąd niezmiernie ważna jest niezmienność jej mikrostruktury.

Praca dotyczy analizy zmian mikro-struktury porów trzech różnych zapraw: cementowej, cementowej z plastyfikatorem i cementowo-wapiennej po 10-letniej ekspozycji na warunki klimatu zewnętrznego w Bydgoszczy. Rozpatruje się trzy strefy kontaktu muru z gruntem: szczelna opaska betonowa, warstwa humusu i żwirowa warstwa filtracyjna.

\section{Metody badawcze}

\subsection{Stanowisko badań in situ}

Poligon doświadczalny do badań in situ zlokalizowano na terenie Uniwersytetu Technologiczno - Przyrodniczego w Bydgoszczy. Stanowisko badawcze obejmuje osiem murów testowych, o gr. 1 cegły i wymiarach 1,61 x 1,42 m. Murki ustawiono szczytami do wyróżnionego na tym terenie kierunku wiatru, ustalonego wg raportów Wojewódzkiego Inspektoratu Ochrony Środowiska w Bydgoszczy. Do ich wykonania użyto cegły klinkierowej pełnej w układzie z ośmioma różnymi rodzajami zapraw, z których sześć miało znany skład materiałowy, a dwie pozostałe były gotowymi - systemowymi, ze wskazaniem zastosowania do murów licowych w celu wyeliminowania wykwitów (rys. 1). Na potrzeby niniejszego opracowania wytypowano 3 mury na zaprawach, których skład podano w tabeli 1. 
Tabela 1. Skład zapraw przyjętych do badań

Table 1. Composition of mortars used for tests

\begin{tabular}{|c|c|c|c|c|c|c|}
\hline \multirow{2}{*}{ Zaprawa } & \multirow{2}{*}{$\begin{array}{c}\text { Proporcje } \\
\text { składników }\end{array}$} & $\begin{array}{c}\text { Cement } \\
42,5 \mathrm{~N}\end{array}$ & Wapno & Piasek & Plast. & \multirow{2}{*}{ Woda } \\
\cline { 3 - 7 } & & {$[\mathrm{kg}]$} & {$[\mathrm{kg}]$} & {$\left[\mathrm{dm}^{3}\right]$} & {$[\mathrm{g}]$} & {$\left[\mathrm{dm}^{3}\right]$} \\
\hline CEM I & $(\mathrm{c}: \mathrm{p})=1: 3,5$ & 3,78 & - & 10,5 & - & 2,53 \\
\hline $\begin{array}{c}\text { CEM I } \\
\text { + plast. }\end{array}$ & $(\mathrm{c}: \mathrm{p})=1: 3,5$ & 3,78 & - & 10,5 & 4,0 & 2,33 \\
\hline C-L & $\begin{array}{c}(\mathrm{c}: \mathrm{w}: \mathrm{p})= \\
1: 1,25: 6,75\end{array}$ & 1,65 & 0,97 & 9,5 & - & 3,04 \\
\hline
\end{tabular}

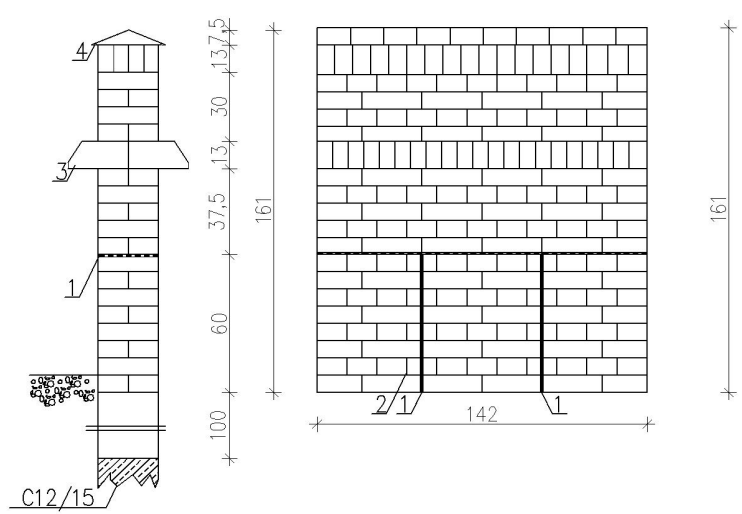

Rys. 1. Mur testowy do badań poligonowych 1 - papa podkładowa - izolacyjna, 2 - kształtka „1/2W”, 3 - kształtka „1K”, 4 - kształtka „DD”

Fig. 1. Test wall for field research 1 - insulating tarpaper underlay, $2-$ $1 / 2 \mathrm{~W}$ fitting, $3-1 \mathrm{~K}$ fitting, $4-\mathrm{DD}$ fitting

W zaprojektowanym murze wykonano izolację przeciwwilgociową na dwóch poziomach: na ścianie fundamentowej ( $10 \mathrm{~cm}$ poniżej poziomu gruntu), $50 \mathrm{~cm}$ nad poziomem gruntu.

Izolacja miała za zadanie zabezpieczyć przed migracją wody z betonowych fundamentów oraz wydzielić obszar narażony na wodę rozbryzgową.

W stanowisku badawczym wymodelowano trzy warianty kontaktu z powierzchnią gruntu (rys. 2): humus z trawnikiem, żwirowa warstwa filtracyjna, szczelna opaska betonowa. 


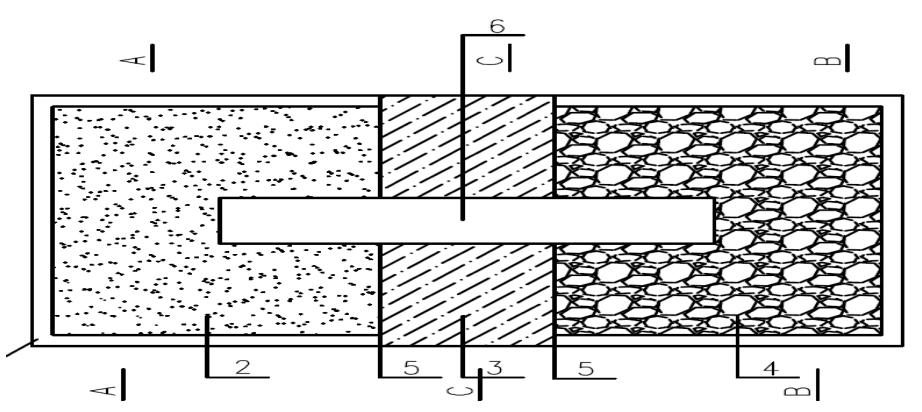

Rys. 2. Ukształtowanie podłoża wokół muru 1 - obrzeża chodnikowe, 2 - ziemia roślinna 3 - opaska betonowa 4 - żwirowa warstwa filtracyjna, 5 - geowłóknina filtrująca, 6 - fundament

Fig. 2. Test wall for field tests 1) underfelt - insulation separating the analysed areas, 2) clinker semifitting, 3) clinker fitting with a single-side edge bevelling, 4) clinker roof, 5) concrete molding, 6) foundations

\subsection{Przygotowanie próbek do badań}

Analizą objęto dwie grupy próbek zapraw:

- w stanie wyjściowym- w trakcie wznoszenia murów z wykonanych zarobów pobrano próbki laboratoryjne, z których uformowano beleczki o wymiarach 40x40x160mm. Po 24h próbki rozformowano, a następnie kondycjonowano w komorze o wilgotności $60 \%$ i temperaturze otoczenia $20 \pm 20 \mathrm{C}$ przez kolejne 27 dni;

- funkcjonujące w 3 murach, poddanych ekspozycji na warunki klimatu zewnętrznego w okresie dziesięciu lat. Z każdego muru pobrano po 2 próbki zapraw o grubości $5 \mathrm{~mm}$, z wyróżnionych obszarów przylegających do 3 różnych podłoży; uzyskany materiał poddano procesowi ekstrakcji soli poprzez wielokrotne płukanie i moczenie.

Tak przygotowane próbki wysuszono do stałej masy w temperaturze $105^{\circ} \mathrm{C}$. Przedstawione wyniki są średnimi arytmetycznymi z dwóch oznaczeń.

\subsection{Badanie porozymetrii rtęciowej}

Badania mikrostruktury wykonano na porozymetrze AutoPore IV seria 9500 wyposażonym w dwa porty: niskiego i wysokiego ciśnienia o maksymalnej wartości 33000 psia (228MPa), co pozwala na pomiar w zakresie mezo i makroporów (od $2 \mathrm{~nm}$ do $360 \mu \mathrm{m}$ ). Przed właściwym badaniem przeprowadzono kalibrację i „blank test” - określające objętość, ściśliwość i efekt termiczny użytego penetrometru. Na podstawie pomiarów kontrolnych ustalono czas równowagi wynoszący $30 \mathrm{~s}$. W wyniku pomiarów przygotowanych próbek ustalono następujące parametry struktury: całkowitą objętość porów, objętość próbki i jej gęstość szkieletową, rozkład objętości porów w funkcji ich średnicy jako zależność całkową i zależność różniczkową. 
Udział objętości porów wyliczono na podstawie wzoru:

$$
\begin{aligned}
& U_{\text {MEZO }}=\frac{\sum_{i=2 n m}^{50 n m} I V_{\text {MEZO }}}{\text { TIV }} \cdot P \\
& U_{\text {MAKRO }}=\frac{\sum_{i=50 \mathrm{~nm}} I_{\text {MAKRO }}}{\text { TIV }} \cdot P
\end{aligned}
$$

gdzie: $\mathrm{IV}_{\mathrm{MAKRO}}$ - \% udział makro-porów $>50 \mathrm{~nm}, \mathrm{IV}_{\mathrm{MEZO}}$ - \% udział mezo-porów 2-50nm, P-porowatość ogólna

\section{Wyniki i dyskusja}

W wyniku badań porozymetrem rtęciowym wyznaczono podstawowe parametry mikro-struktury. Na podstawie przeprowadzonych badań stwierdzono, że w wyniku 10 lat eksploatacji murów licowych nastąpiły zmiany w mikrostrukturze zapraw w różnych rozwiązaniach kontaktu muru z podłożem obejmujące zarówno mezo- jak i makro-pory (tabela 2,3,4).

Tabela 2. Podstawowe parametry mikrostruktury badanych próbek zaprawy CEM I

Table 2. Basic parameters of microstructure for tested CEM I mortar samples

\begin{tabular}{|l|c|c|c|c|}
\hline \multirow{2}{*}{$\begin{array}{l}\text { Parametry } \\
\text { mikrostruktury }\end{array}$} & \multirow{2}{*}{$\begin{array}{c}\text { Próbki } \\
\text { wyjścio- } \\
\text { we }\end{array}$} & \multicolumn{2}{|c|}{ 10 lat ekspozycji na środowisko } \\
\cline { 4 - 5 } & humus & $\begin{array}{c}\text { opaska } \\
\text { betonowa }\end{array}$ & $\begin{array}{l}\text { żwirowa } \\
\text { warstwa }\end{array}$ \\
\hline Intruzja rtęci, mL/g & 0,109 & 0,1246 & 0,0982 & 0,1108 \\
\hline Gęstośćcojętościowa, g/mL & 1,9664 & 1,9231 & 2,0441 & 1,9867 \\
\hline Gęstość właściwa, g/mL & 2,5029 & 2.5289 & 2,5577 & 2,5473 \\
\hline Porowatość\% & 23,96 & 23,97 & 20,08 & 22,01 \\
\hline Mezopory 2-50nm, \% & 20,61 & 20,49 & 16,51 & 18,80 \\
\hline Makropory> 50nm, \% & 0,82 & 3,48 & 3,57 & 3,21 \\
\hline
\end{tabular}

W zaprawach cementowych CEM I i z plastyfikatorem, niezależnie od rozwiązania kontaktu z podłożem, stwierdzono podobną tendencję zmian: wzrosła gęstość właściwa przy jednoczesnym spadku porowatości. Udział makro-porów znacząco zwiększył się, zwłaszcza w kontakcie muru ze szczelną opaską betonową (z poziomu 0,82 do nawet 3,57\% dla zaprawy cementowej CEM I, z 1,02 do 4,06 dla zaprawy cementowej z plastyfikatorem). Natomiast udział mezoporów zmniejszył się. Jest to szczególnie widoczne w kontakcie muru z opaską betonową (z poziomu 20,61 do nawet 16,51\% dla zaprawy cementowej CEM I, z 21,16 do 17,48\% dla zaprawy cementowej z plastyfikatorem). 
Tabela 3. Podstawowe parametry mikrostruktury badanych próbek klinkieru z muru na zaprawie CEM I z plastyfikatorem

Table 3. Basic parameters of microstructure for tested CEM I with plasticizer mortar samples

\begin{tabular}{|l|c|c|c|c|}
\hline \multirow{2}{*}{$\begin{array}{l}\text { Parametry } \\
\text { mikrostruktury }\end{array}$} & \multirow{2}{*}{$\begin{array}{c}\text { Próbki } \\
\text { wyjściowe }\end{array}$} & 10 lat ekspozycji na środowisko \\
\cline { 4 - 5 } & & humus & $\begin{array}{c}\text { opaska } \\
\text { betonowa }\end{array}$ & $\begin{array}{c}\text { żwirowa } \\
\text { warstwa }\end{array}$ \\
\hline Intruzja rtęci, mL/g & 0,1127 & 0,1046 & 0,1075 & 0,1096 \\
\hline Gęstośćobjętościowa, g/mL & 1,9686 & 2,0446 & 2,0042 & 1,9906 \\
\hline Gęstość właściwa, g/mL & 2,5297 & 2,6009 & 2,5543 & 2,5463 \\
\hline Porowatość\% & 22,18 & 21,39 & 21,54 & 21,82 \\
\hline Mezopory 2-50nm, \% & 21,16 & 18,33 & 17,48 & 19,25 \\
\hline Makropory> 50nm, \% & 1,02 & 3,05 & 4,06 & 2,57 \\
\hline
\end{tabular}

Tabela 4. Podstawowe parametry mikrostruktury badanych próbek klinkieru z muru na zaprawie cementowo-wapiennej

Table 4. Basic parameters of microstructure for tested cement-lime mortar samples

\begin{tabular}{|l|c|c|c|c|}
\hline \multirow{2}{*}{$\begin{array}{l}\text { Parametry } \\
\text { mikrostruktury }\end{array}$} & \multirow{2}{*}{$\begin{array}{c}\text { Próbki } \\
\text { wyjścio- } \\
\text { we }\end{array}$} & \multicolumn{2}{|c|}{ 10 lat ekspozycji na środowisko } \\
\cline { 4 - 5 } & humus & $\begin{array}{c}\text { opaska } \\
\text { betonowa }\end{array}$ & $\begin{array}{c}\text { żwirowa } \\
\text { warstwa }\end{array}$ \\
\hline Intruzja rtęci, mL/g & 0,1226 & 0,1408 & 0,1501 & 0,1141 \\
\hline Gęstość objętościowa, g/mL & 1,9443 & 1,8679 & 1,8669 & 2,0192 \\
\hline Gęstość właściwa, g/mL & 2,5526 & 2,5646 & 2,5935 & 2,6239 \\
\hline Porowatość\% & 23,83 & 26,30 & 28,02 & 24,04 \\
\hline Mezopory 2-50nm, \% & 17,65 & 23,45 & 26,33 & 21,94 \\
\hline Makropory> 50nm, \% & 6,18 & 2,85 & 1,69 & 2,10 \\
\hline
\end{tabular}

Zaprawa cementowo-wapienna po 10 latach eksploatacji charakteryzuje się zmianami mikrostruktury odbiegającymi od opisanych wyżej zapraw cementowych. Porowatość w pobranych próbkach jest wyższa od próbki wyjściowej, ukształtowana jest przede wszystkim przez mezopory, których udział znacznie wzrósł niezależnie od kontaktu z podłożem. Zmniejszył się udział makroporów w przypadku szczelnej opaski betonowej z poziomu 6,18 do 1,69\%. Powyższe obserwacje odzwierciedlają przebiegi krzywych całkowych rozkładu wielkości porów (rys. 3) w zaprawie cementowo-wapiennej. 


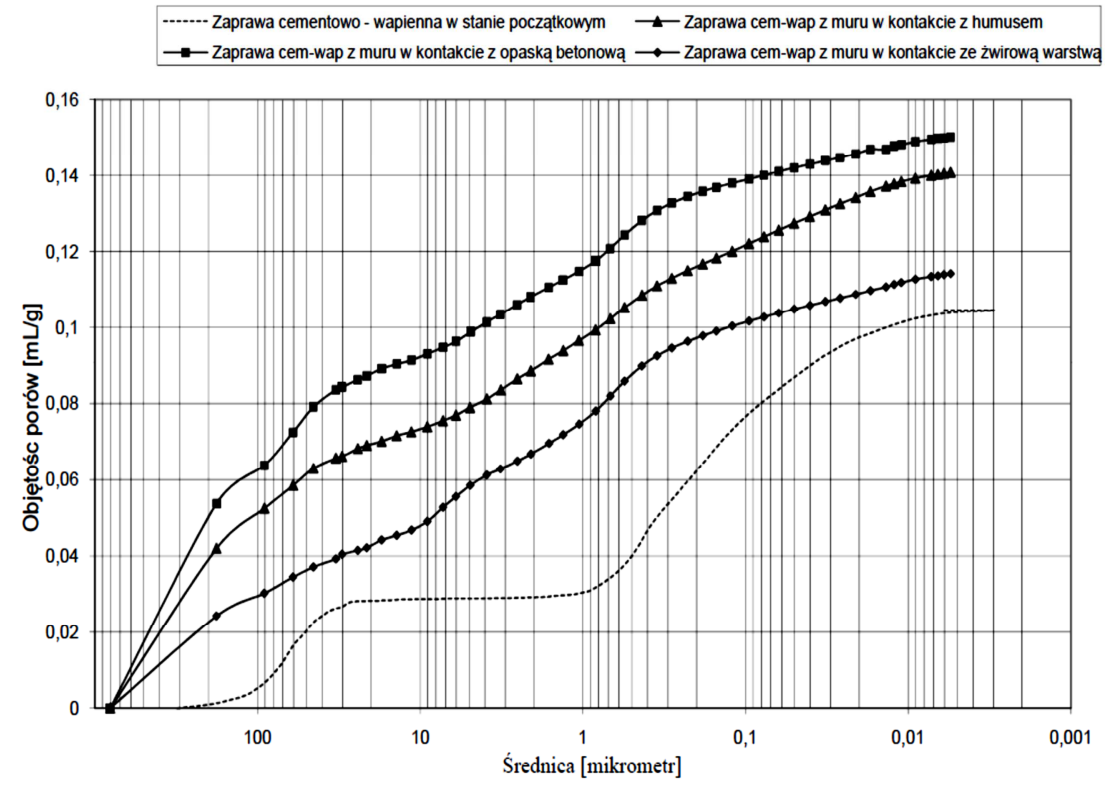

Rys. 3. Krzywa całkowa rozkładu wielkości porów w zaprawie cementowo-wapiennej

Fig. 3. Cumulative intrusion vs diameter of cement-lime mortar

\section{Podsumowanie}

W pracy przeanalizowano zmiany mikrostruktury zapraw pod wpływem wieloletniej ekspozycji na środowisko zewnętrzne, z uwzględnieniem różnego rozwiązania podłoża wokół muru. Kontakt muru z szczelną opaską betonową powodował znaczne zmiany w mikrostrukturze zapraw. Najmniejsze zmiany stwierdzono w rozwiązaniu ze żwirową warstwą filtracyjną. Dodatek plastyfikatora do zaprawy cementowej nie wpłynął znacząco na parametry mikrostruktury. Istotny jest natomiast wpływ wapna, gdzie obserwuje się zmniejszenie udziału makro-porów na korzyść mezo-porów przy jednoczesnym wzroście porowatości. Otrzymane wyniki pokazują jednoznacznie zmiany objętości makro- i mezoporów w zaprawach pobranych z powierzchniowej warstwy spoin. Stwierdzone zmiany są prawdopodobnie wywołane krystalizacją soli i rozwojem mikro-rys wskutek tego procesu.

\section{Literatura}

[1] PN-EN 1996 Eurokod 6: Projektowanie konstrukcji murowych.

[2] Kurdowski W.: Chemia cementu i betonu, Wydawnictwa Naukowo PWN, Warszawa 2010. 
[3]Wesołowska M., Pawełkowski K., Kempiński M., Kaczmarek M.: Compatibility of masonry components from gas permeability tests [P] Proceeding of 8th International Masonry Conference, Dresden, 2010.

[4] HenkelD., Pense A W.: Structures and Properties of Engineering Materials [J]. Mc GrawHill Series in Materials Science, 2002.

[5] Van Vlack LH.: Elements of Materials Science and Engineering Addison-Wesley Publishing Company, 1989.

[6] Brocken H.J.P., Pers N.M., Larbi J.A.: Composition of lime-cement and air-entrained cement mortar as a function of distance to the brick-mortar interface: consequences for masonry. Mater Struct; 2000 33:634-46.

Praca powstała z wykorzystaniem aparatury zakupionej w ramach projektu „Realizacja II etapu Regionalnego Centrum Innowacyjności” współfinansowanego ze środków Europejskiego Funduszu Rozwoju Regionalnego w ramach Regionalnego Programu Operacyjnego województwa kujawsko - pomorskiego na lata 2007 - 2013.

\section{ANALYSIS OF MICRO-STURCTURAL CHANGES OF CLINKER BRICK WALL MORTARS AFTER LONG EXPOSITION TO THE CLIMATIC CONDITIONS OF POLAND}

\section{S u m m a r y}

Facial walls are exposed to continuous influence of surrounding environment. This influence contributes to structure destruction, lower its durability. Mortars belong to a group of chemically active materials, undergoing both internal and external corrosion. External corrosion includes all cases where mortar is threatened with undesirable external factors $\left(\mathrm{CO}_{2}\right.$ gas, acid rain, changing temperatures often below freezing point of water, mineral salt solutions coming from surrounding elements). The internal corrosion originates from mortar compound themselves. The above mentioned factors essentially influence mortar microstructure changes. This process is distributed in time.

The researches were led on the field test area localized at the University of Science and Technology in Bydgoszcz. Three facial walls were analyzed with different mortars. During the subsequent years of wall existence efflorescences were noticed appearing in different range and intensity. The data collected let us define the area of the most intensive efflorescence. After ten years, for each wall from a preselected place, mortar samples were taken which microstructure was examined with Mercury Intrusion Porosimetry (MIP) method. Such obtained results were used to evaluate changes in meso- and macropore distribution resulted from external environment influence.

Keywords: facial wall, mortar microstructure, environment at deterioration

Przestano do redakcji: 07.06.2016 r.

Przyjęto do druku: 30.06.2016 r.

DOI: $10.7862 / \mathrm{rb} .2016 .8$ 